\title{
Pontes diplomáticas e arte política Alkantara 2008
}

\section{Alexander Gerner}
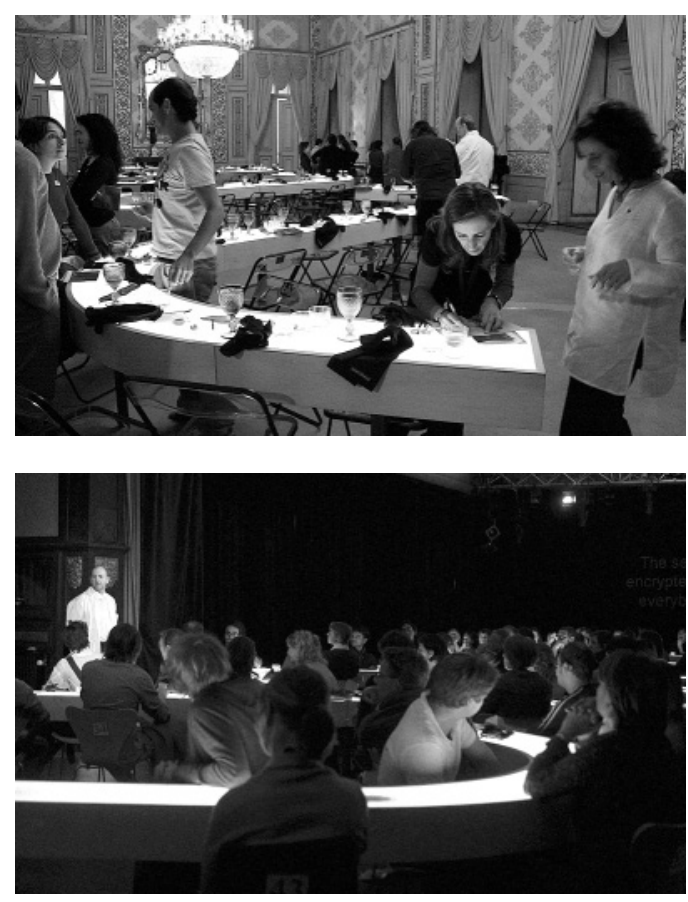

A segunda edição da bienal de artes performativas Alkantara Festival ("ponte" em árabe) passou por vários espaços em Lisboa entre 22 de Maio e 6 de Junho de 2008. Num artigo de apresentação que a anunciava, o programador Marc Deputter (2008: 5) propôs como tema central o "novo teatro político", numa linha diferente da do teatro político de contestação e de intervenção social e política dos anos 60 e 70, que declarou - numa perspectiva historicista - como ultrapassado.

As artes performativas vivem actualmente uma situação polémica em relação ao político: algures entre o póspolítico e a micro-política. Neste sentido, há uma abordagem pós-política e pós-histórica presente no espectáculo Conservatório, do Teatro Praga, e em textos acerca do "pós-humano", como em Banquete, de Patrícia Portela. Identificamos ainda essa problemática da micro-política em Chácara Paraíso (Kaegi/Arias) e em Bonanza (colectivo Berlin), bem como nos espectáculos sobre viagens identitárias, como são Doo, de Miguel Pereira, e China, de William Yang.

0 Festival Alkantara supostamente celebra a nova vaga da arte performativa política, mas talvez fosse mais apropriado falar de "micro-diplomacia performativa", no sentido de fazer pontes entre comunidades e espaços, entre espectadores e profissões, entre testemunhos de viagens
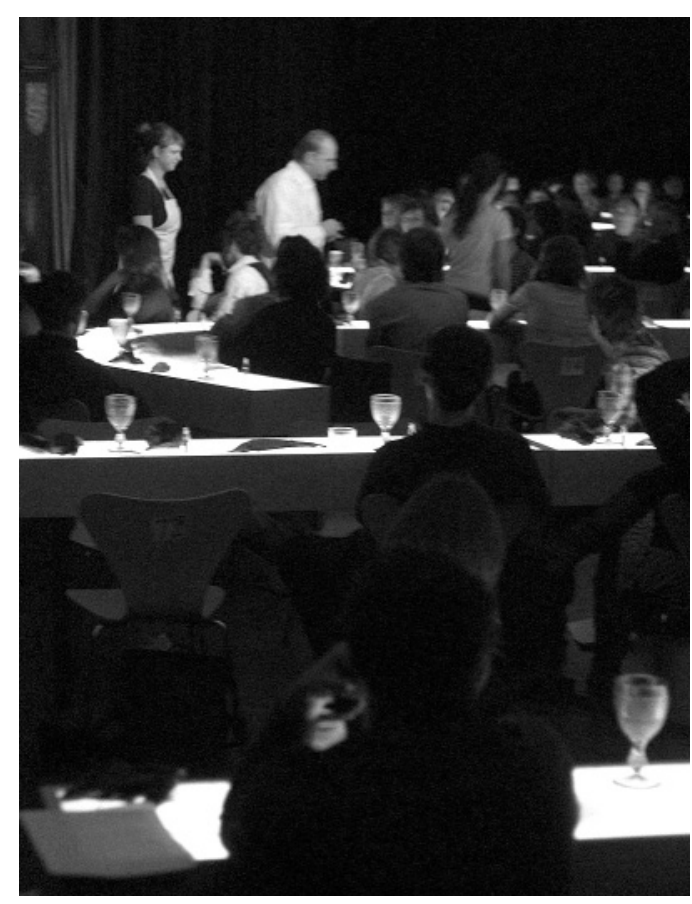

e a memória. Porque, de facto, produções como Chácara Paraíso ou Bonanza afastam-se de um teatro político de activismo directo e concentram-se no mundo sócioantropológico do trabalho e do lugar. Quando Deputter introduz o projecto Chácara Paraíso como questionamento do próprio conceito de comunidade, atribui aos autores Stefan Kaegi e Lola Arias um discurso da política da comunidade, que aparentemente está mais presente no documentário-espectáculo Bonanza.

Outra questão que se pode levantar a propósito desta edição do Alkantara é o caso da "ponte" entre uma comunidade da Cova da Moura e o espaço de apresentação, o CCB. Neste caso - o do trabalho da coreógrafa Filipa Francisco com residentes desse bairro - pode correr-se o risco de confundir um acto écticoe social com um acontecimento político ao destacar uma lógica da ética da inclusão e da abertura dos lugares da cultura aos agentes culturais marginais ou culturalmente definidos como tal. É que a boa vontade, que produz "pontes éticas" para culturas etnicamente diferentes pode, em rigor, não só reforçar fronteiras étnico-culturais dentro de uma cidade cosmopolita como Lisboa, como confundir a ordem da ética e da inclusão cultural, através do acontecimento de um novo teatro político.
$<>$

Banquete,

de Patricia Portela, 2008, < fot. Maria João Soares; $\checkmark$ fot. Gianina Urmeneta. [cortesia Alkantara Festival]
Alexander Gerner é bolseiro da FCT em Filosofia e investigador no projecto "A Imagem em Ciência e na Arte” (CFCUL). É dramaturgo e autor de vários projectos de teatro. 


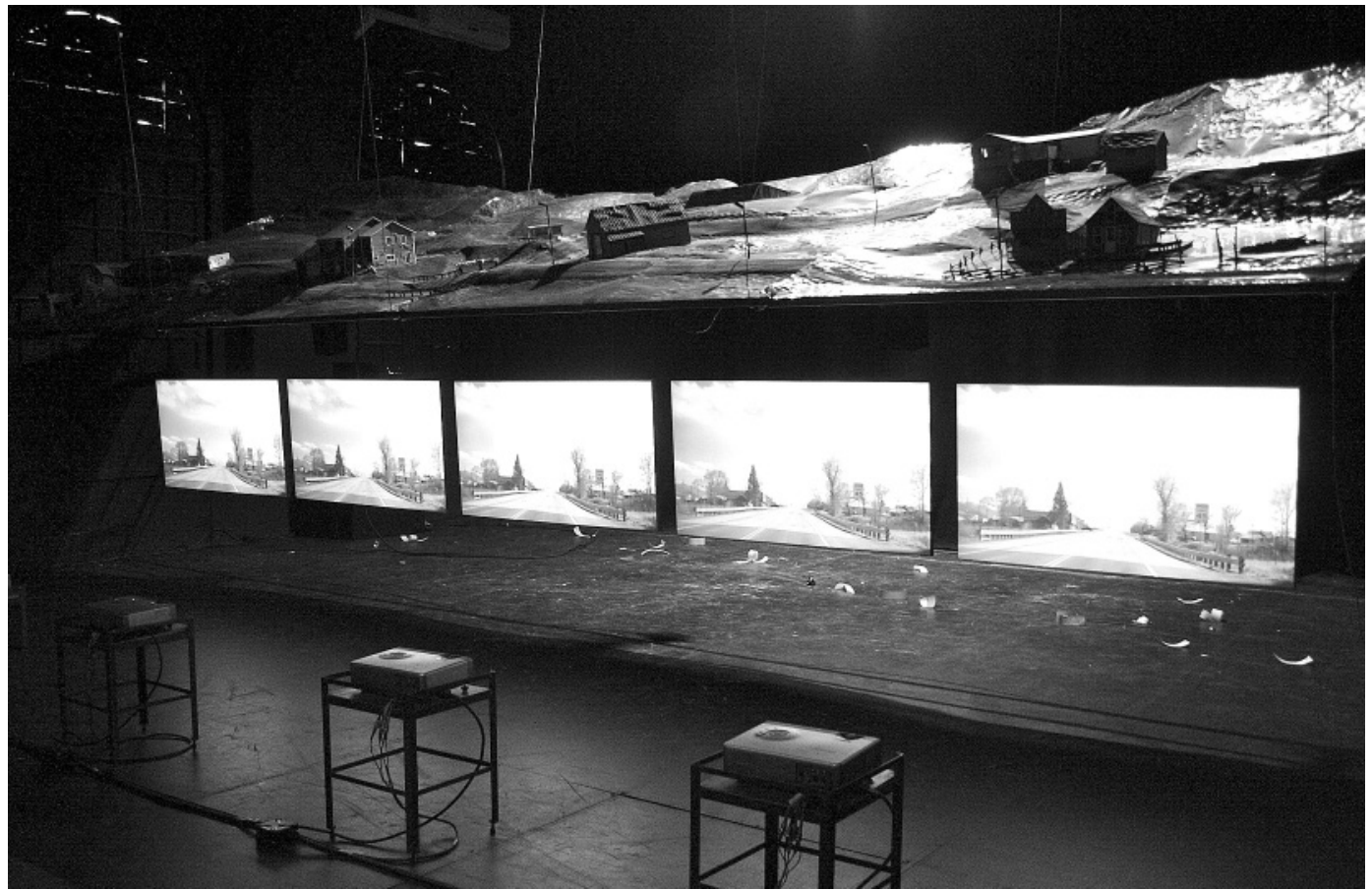

Vejamos aqui a perspectiva sobre o político e o estético desenvolvida desde os anos 90 por Jacques Rancière, 0 filósofo da política radical-democrata da divergência e do desentendimento. Ele define o político como um acontecimento acidental que resulta do "desentendimento" acerca da realidade sensivel (dos corpos) num espaço comum, o que possibilita um novo posicionamento das lógicas - fixadas pela ordem dominante - isto é, a justiça os grupos de interesse do poder ou até os agentes culturais. Estes são designados por Rancière como a ordem da "polícia", cada vez que não dão voz aos que não têm o poder do discurso, e enquanto não criam um palco próprio para dar visibilidade aos problemas da desigualdade: "A polícia pode ser doce e amável, mas continua a ser, mesmo assim, o contrário da política" (Rancière 1996: 43). Pelo contrário, o político, que interrompe a ordem das parcelas e das vozes distribuídas, no momento de se desentender com a ordem desigualmente instalada, abre a possibilidade de uma lógica diferente, e reabre as regras para criar um novo jogo e novos palcos para a interrupção da desigualdade

A doce e amável polícia militar de São Paulo "Quando me perguntam quantas pessoas matei, eu não respondo": apontamento na parede de um ex-polícia de S. Paulo do tempo da ditadura brasileira, em Chácara Paraiso.

Kaegi e Arias não questionam a comunidade, mas apropriam-se dos especialistas e dos seus currículos como pano de fundo para mostrar um grupo profissional - a polícia - no seu mundo do trabalho e no seu refúgio para lá do trabalho (bailarina de samba, taxista, treinador de cães, etc.).

"Mostra de arte polícia" era como Stefan Kaegi e Lola Arias chamavam ao projecto antes da sua apresentação em Lisboa. Oferece-se como um "mausoléu policial em estações" - às vezes dolorosas para um espírito crítico de vários performersque ainda são, ou já foram, polícias em Chácara Paraíso, a maior escola de polícia militar em
São Paulo. Um dos elementos unificadores entre os performers é que todos têm uma história familiar, até de várias gerações, ligada ao "policial". Assim, em vez de um teatro feito por especialistas do teatro (actores,

dramaturgos, encenadores), surge um teatro de peritos em certas áreas profissionais da vida quotidiana. Através das suas histórias, confraternizamos com Ágata, a cadela polícia, Paulo, Roberto, Pedro, Flávia, Amorim que, apesar de aceitarem que os espectadores Ihes façam perguntas sobre aquela realidade, não contribuem para um discurso reflexivo e crítico acerca da sua condição profissional. Tudo parece ficar morto nessa memória pessoal atomizada em mini-retratos, e nada abre para caminhos da reflexão, sejam eles de ordem estética ou política. Ao ser questionada a razão pela qual o ex-polícia não quer responder acerca de quantas pessoas já matara nas suas funções policiais impossibilita-se um diálogo com o público: "Porque fomos sempre muitos a disparar, e ninguém sabe ao certo em quem acertou."

Mas é preciso ter em conta a profunda, e até radical, mudança estética introduzida pelo teatro da Escola de Giessen, a mais inovadora escola alemã desde os anos 90, e que identificamos nas formações onde Kaegi participa, como os Rimini Protokoll (que em Abril de 2008 receberam o Prémio Europa para as Novas Realidades) e os Higiene Heute (cf. Dreysee et al. 2007).

\section{0 político entre a memória e o esquecimento do humano}

0 Banquete sempre foi celebrado para finalizar e iniciar algo de novo. Na versão de Patrícia Portela, celebra-se um recomeço da história "humana, demasiada pós-humana", num jantar de nouvelle cuisine em corolários de uma narrativa esotérica e ironizante entre a genética e a culinária.

Este banquete alimenta-se de referências ao terramoto e a outras catástrofes, o que implica uma possibilidade de recomeçar a história. 0 público (50 pessoas) encontravase em mesas arrumadas em forma de partes de cromossomas, iluminadas de baixo. A obrigatoriedade de 

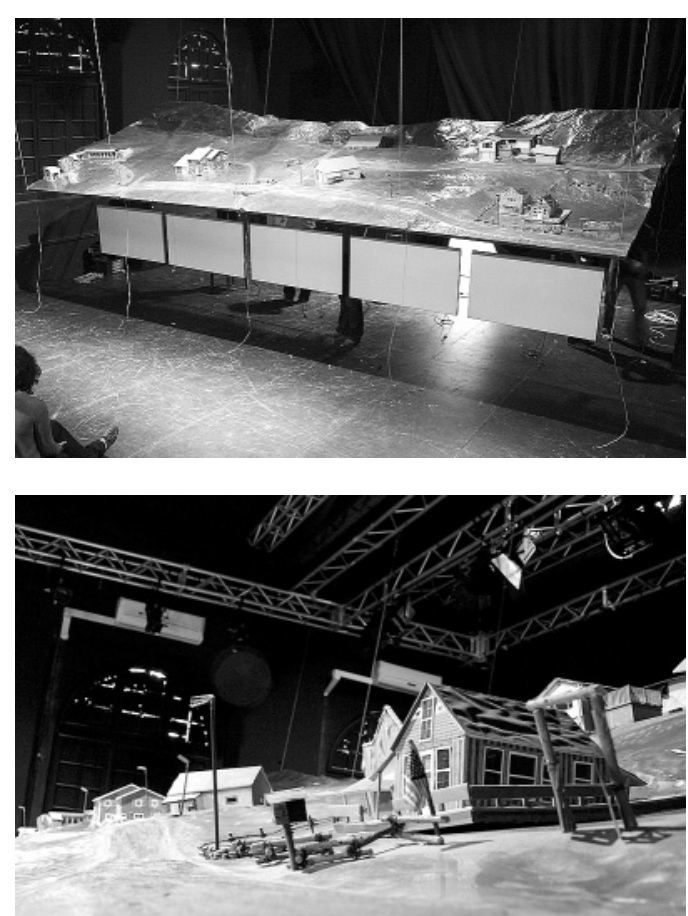

provar comida e bebida de "alta" produção, forçava o público a utilizar o olfacto, confiando, assim, num equilibrio entre fome e espírito experimental em relação à

alimentação performativa e desconhecida do catering teatral que se apresentava como um "terceiro sector do teatro interdisciplinar".

Portela cita e transforma a reunião da primordial comédia do teatro grego, os Pássaros de Aristófanes, na sua versão "conferências dos pássaros" sobre a "lei natural", a natalidade, a sobrevivência e a longevidade do homem em tempos da engenharia genética e da comida geneticamente modificada e dando assim ao humano uma "segunda oportunidade". Mas, em vez de invocar um "estado" ou até o estado das coisas e os seus parlamentos, como nos Pássaros, procura-se um recomeço pelo pacto sonhador com o "diabo" das ciências naturais e biológicas como última ilusão iluminista, como escreve Portela:

"A última geração de homens biológicos, a clonarem-se a si próprios, aceitando a manipulação da humanidade, da matéria humana, oferecendo-se uma segunda oportunidade".

No Banquete de Patrícia Portela, ouvem-se textos acerca da clonagem e outras entrevistas fabricadas na "cozinha da escrita" e, analogamente à "politiquice" (que significa desvio aos assuntos importantes da política), poderia invocar-se a propósito deste seu trabalho a "cientifiquice". Ou seja, o espectáculo partilha um discurso pop (com entrevistas a cientistas), ao qual a autora adicionou especiarias tradicionais de reflexão sobre teatro, como foi, por exemplo, o caso de Heinrich von Kleist no seu Teatro das marionetas. Dele acolhe a (im)possivel viagem para uma segunda inocência do humano póshistórico, depois da volta ao mundo para reencontrar o paraiso do esquecimento, bem como de um recomeço pelo tempo iluminista e científico de hoje em dia.

0 Banquete acaba com queijo e vinho à portuguesa, sinal de que nem tudo hoje se reduz a questões de nouvelle cousine do humano, demasiado pós-humano: "nada se perdeu e nem tudo se transformou".

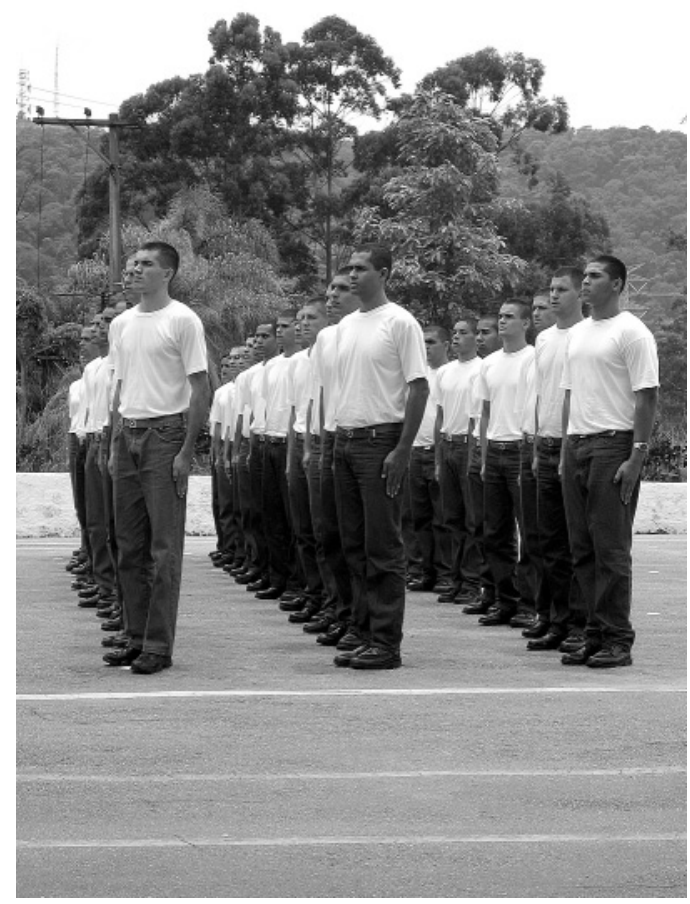

$\checkmark$

do colectivo

Berlin, 2008,

fot. Maria João Soares.

Chácara Paraiso, de Stefan Kaegi

et Lola Árias,

SESC-Paulista [cortesia Alkantara Festival]

Viagens identitárias ao limite da auto referencialidade do artista como instituição "crítica" de si

0 espectáculo China, do performer-fotógrafo australiano William Yang (no Museu do Oriente), insere-se na categoria das viagens identitárias, a que também pertence Doo, de Miguel Pereira, que criou um espectáculo a partir de uma viagem a Moçambique, a terra perdida onde - em Lourenço Marques, hoje Maputo - havia uma casa portuguesa da sua família. No programa desta edição do Alkantara, Doo é apresentado na continuação lógica de um espectáculo de 2006, Karima meets Lisboa meets Miguel meets Cairo, uma "colaboração" em duas partes com a coreógrafa egípcia Karima Mansour. Na primeira parte do espectáculo de 2006, Miguel Pereira utilizava a estratégia de ironizar uma forma da crítica às instituições aparecida nos anos 60/70 (cf. Smithson), mas transportada para o discurso "do outro" no debate intercultural de hoje em dia. Na segunda, Karima confronta a expectativa de um olhar ocidental em relação a si como coreógrafa árabe no pós-11 de Setembro. Pereira utiliza ainda uma estratégia de "crítica interna" às instituições que o deixaram viajar para se encontrar com Karima e com ela trabalhar, processo que Fraser (2005) intitula de "instituição da crítica", o que implica inclusão da autocrítica e a crítica à instituição que financia o projecto.

Nesses dois espectáculos de 2006 havia uma espécie de laboratório conflitual e de desentendimento entre culturas críticas e abordagens artísticas diferentes relativamente a uma moldura cultural ontologizante que impõe aos artistas a necessidade do encontro, promovida e financiada por uma curadoria internacional. Como lidar com a autonomia criativa quando há esse compromisso com o encontro intercultural de uma estrutura internacional em rede? Como retirar do lado diplomático dessa tarefa (meets... meets... meets) o aspecto político ou crítico?

A utilização do primeiro dos Concertos de Brandenburgo, de Bach, no início do espectáculo Doo serve como referência óbvia a um lugar inicial impossivel de reencontrar. 0 objecto retro-analógico do vinil riscado transmite o erro de um gesto repetido que se esgota num 

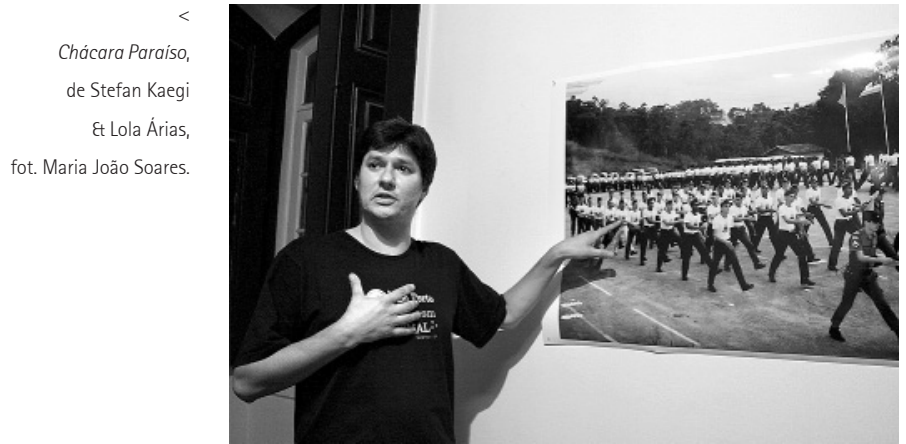

cansaço da história - inscrito no corpo preto do disco, manipulado pela mão (em) branco dele - tropeçando na cultura ocidental de Johann Sebastian Bach como um regresso à primeira experiência de palco em Lourenço Marques. Pereira tenta revisitar o "já não seu" lugar de nascimento (Lourenço Marques colonial), lugar distópico parte musical num gesto obsessivo e obviamente perdido, no sentido de "já não pertenço lá, mas aqui também não", e a mesma aniquilação do ritmo dos batuques rápidos do performer moçambicano é transformado em techno-beat. Disso resulta uma inquietação calada nos últimos 20 minutos do espectáculo em que ambos, os do palco, incluindo o músico looper ao vivo, e o público, esperaram o fim do beat para deixar morrer o espectáculo e a memória do lugar impossivel de revisitar. 0 mais interessante dessa lógica da continuação de 2006 é que, no fim do espectáculo de 2008, a crítica à curadoria se repete, enquanto ele se coloca na posição do curador passivo num banco atrás no palco, vendo e ouvindo o "seu" espectáculo finalizar-se, sem mais interagir.

\section{A questão da pequena comunidade}

Bonanza é um retrato filmico do grupo Berlin, de Antuérpia, instalado em cinco projecções de vídeo por baixo de uma maqueta (7x3metros), sem performers ao vivo. A maqueta representa as casas dos 7 habitantes permanentes dessa antiga cidade mineira, abandonada ao longo do tempo, onde antigamente viviam cerca de 6 mil pessoas à procura da riqueza rápida. Tudo se resume à dificuldade de viver numa comunidade, que se torna quase uma comunidade de fantasmas, já que os habitantes não falam uns com os outros, mas têm opiniões, lançam e refutam boatos acerca dos outros. Uma das poucas cidadãs põe o dedo na ferida explicando a lógica de Bonanza: "Quanto mais pequena é uma comunidade, mais conflitos há". Há um jogo dramático que assenta em imagens paradas, algumas entrevistas e pouca acção que caracterizam esse "lugar caverna" de fuga a uma civilização incerta. Mas em momentos fortes desse jogo, destaca-se a complexidade dos retratos sociais e institucionais presentes nos documentários de Wiseman: em nenhum momento se consegue decidir quem tem ou não razão.

Em Bonanza mostra-se a incapacidade de o individuo viver ao lado do seu vizinho, num lugar remoto à margem da "grande sociedade", e ao mesmo tempo deixá-lo em paz. E revelam-se preconceitos e mesmo efabulações acerca das mortes que o vizinho podia ter na sua cave. Se, por um lado, há uma procura doentia de calma e distância relativamente ao mundo "civilizado", por outro, surge a questão de saber que relação existe entre a condição de
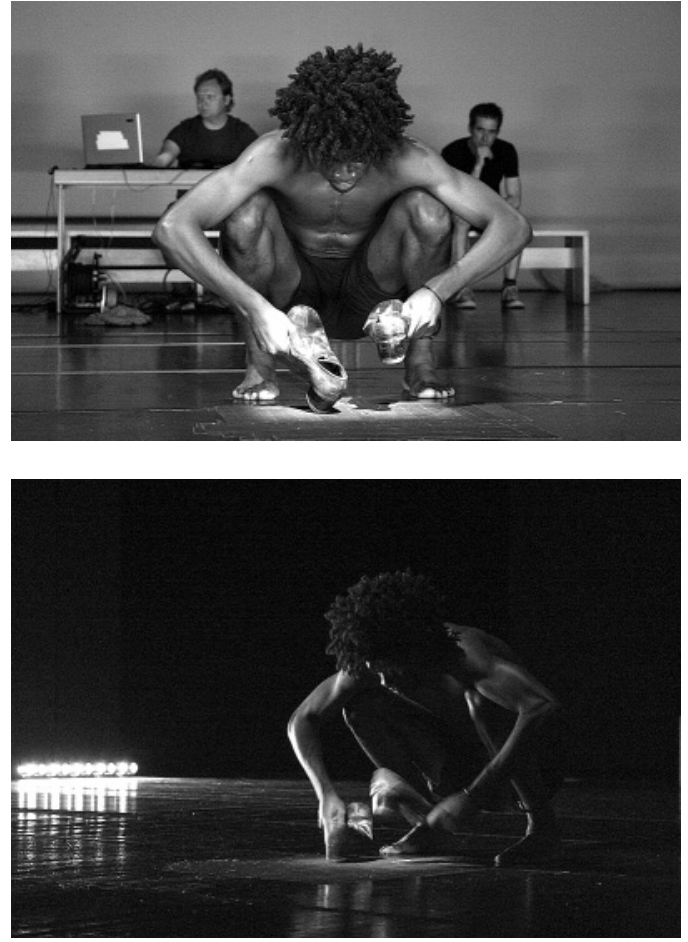

criar e o retiro. A necessidade obsessiva da calma absoluta, procurada pelos habitantes de Bonanza, repõe justamente a questão do social no centro do espectáculo, pelo que este se torna político. Até porque coloca uma pergunta simples: a quem pertence um lugar? E a partir dessa pergunta simples gera-se o drama quase cosmo-político: quem fugiu para aqui e porquê? Por que razão muitos têm casa na cidade mais próxima, Pueblo, e não só em Bonanza? Quem tem direito de falar - nesse lugar deserto - da vida mineira do passado? Só os que sempre tiveram casa ali? Ou também os do Pueblo que visitam Bonanza? Quais as regras do jogo das fronteiras da pertença?

O lugar "idílico" de Bonanza parece uma nova abordagem de Huis Clos (Sartre) misturado com o tribunal da caça às Bruxas de Salém (Miller), em que o paraíso da comunidade distante, pequena e profunda, facilmente se torna um inferno do outro, em que "civilizados" põem os vizinhos em tribunal. Assim, Bonanza, pelo retrato que desenha dessa micro-sociedade, marcada pelas vozes dissonantes e opiniões desencontradas, e em que todos os habitantes se questionam acerca do direito de falar desse mesmo lugar, concretiza um acontecimento da arte política na última edição do Alkantara Festival.

\section{Referências bibliográficas}

DEPUTTER, Marc (2008), "O novo teatro político: Nada se perde, tudo se transforma", Le monde diplomatique, ed. portuguesa, Maio, p. 5.

DREYSEE, M. / MALZACHER, F.(Ed.) (2007), Experten des Alltags. Das Theater von Rimini Protokoll[ [Peritos do quotidiano: 0 teatro de Rimini Protokol], Berlim, Alexander Verlag.

FRASER, Andrea (2005), "From the Critique of Institutions to an Institution of Critique", Artforum, 44, n. 1 , Setembro, 278-283

RANCIĖRE, Jacques (1996), 0 desentendimento: Politica e filosofia, São Paulo, Editora 34.

SMITHSON, Robert (1972), "Cultural Confinement", in http://www.robertsmithson.com/essays/cultural.htm 